Meta

Journal des traducteurs

Translators' Journal

\title{
Translating Tea: On the Semiotics of Interlingual Practice in the Hong Kong Museum of Tea Ware
}

\section{Robert Neather}

Volume 53, numéro 1, mars 2008

Le verbal, le visuel, le traducteur

The Verbal, the Visual, the Translator

URI : https://id.erudit.org/iderudit/017984ar

DOI : https://doi.org/10.7202/017984ar

Aller au sommaire du numéro

Éditeur(s)

Les Presses de l'Université de Montréal

ISSN

0026-0452 (imprimé)

1492-1421 (numérique)

Découvrir la revue

Citer cet article

Neather, R. (2008). Translating Tea: On the Semiotics of Interlingual Practice in the Hong Kong Museum of Tea Ware. Meta, 53(1), 218-240.

https://doi.org/10.7202/017984ar
Résumé de l'article

Cette étude considère la pratique de la traduction interlinguale dans le musée et porte particulièrement sur la façon dont les éléments visuels contraignent la traduction de textes verbaux ou déterminent la forme de cette traduction. Le musée représente un environnement sémiotique particulièrement complexe dans lequel il y a une interaction entre de nombreux systèmes de signification (systèmes verbaux, visuels, spatiaux) dans le but de produire un sens holistique qu'on a désigné " combinatoriel et relationel ». De telles interactions se produisent sur le plan intrasémiotique (par exemple entre objets, entre objets et photos ou entre textes), ainsi que sur le plan intersémiotique (c'est à dire entre ces divers éléments verbaux et visuels). La traduction interlinguale devrait tenir compte de ces polarités multiples pour arriver à produire un texte cible efficace.

Cette étude porte spécifiquement sur le Museum of Tea Ware à Hong Kong pour considérer comment diverses contraintes sémiotiques influent sur la production de textes cibles en anglais en partant de textes sources chinois. Une contrainte de la sorte est celle de l'esthétique spatiale, la façon de placer le texte en relation aux images ou aux objets saillants dans un ensemble donné. Une deuxième contrainte est la nature générique du texte définie par sa position dans la hiérarchie des textes de musée. En troisième lieu, et en plus grand détail, l'étude soutient la thèse que la nature de la modification trouvée dans le texte cible est en proportion directe de la relation entre les éléments verbaux et visuels, selon que cette relation soit paradigmatique ou syntagmatique.
Ce document est protégé par la loi sur le droit d'auteur. L'utilisation des services d’Érudit (y compris la reproduction) est assujettie à sa politique d'utilisation que vous pouvez consulter en ligne.

https://apropos.erudit.org/fr/usagers/politique-dutilisation/ 


\title{
Translating Tea: On the Semiotics of Interlingual Practice in the Hong Kong Museum of Tea Ware
}

\author{
ROBERT NEATHER \\ City University of Hong Kong, Kowloon, Hong Kong \\ ctneathe@cityu.edu.hk
}

\section{RÉSUMÉ}

Cette étude considère la pratique de la traduction interlinguale dans le musée et porte particulièrement sur la façon dont les éléments visuels contraignent la traduction de textes verbaux ou déterminent la forme de cette traduction. Le musée représente un environnement sémiotique particulièrement complexe dans lequel il y a une interaction entre de nombreux systèmes de signification (systèmes verbaux, visuels, spatiaux) dans le but de produire un sens holistique qu'on a désigné «combinatoriel et relationel». De telles interactions se produisent sur le plan intrasémiotique (par exemple entre objets, entre objets et photos ou entre textes), ainsi que sur le plan intersémiotique (c'est à dire entre ces divers éléments verbaux et visuels). La traduction interlinguale devrait tenir compte de ces polarités multiples pour arriver à produire un texte cible efficace.

Cette étude porte spécifiquement sur le Museum of Tea Ware à Hong Kong pour considérer comment diverses contraintes sémiotiques influent sur la production de textes cibles en anglais en partant de textes sources chinois. Une contrainte de la sorte est celle de l'esthétique spatiale, la façon de placer le texte en relation aux images ou aux objets saillants dans un ensemble donné. Une deuxième contrainte est la nature générique du texte définie par sa position dans la hiérarchie des textes de musée. En troisième lieu, et en plus grand détail, l'étude soutient la thèse que la nature de la modification trouvée dans le texte cible est en proportion directe de la relation entre les éléments verbaux et visuels, selon que cette relation soit paradigmatique ou syntagmatique.

\section{ABSTRACT}

This paper explores the nature of interlingual translation practice in the museum, focusing in particular on the ways in which visual elements shape or constrain the translation of verbal texts. The museum represents a particularly complex semiotic environment in which various systems of signification (verbal, visual, spatial) interact to produce meaning in a way that is said to be "combinatorial and relational." Such interactions take place both at intra-semiotic levels (e.g. between objects, between objects and photographs, or between texts) and inter-semiotic levels (between these various verbal and visual elements). Interlingual translation must negotiate such multiple polarities if an effective target text is to be produced.

The paper focuses on the Museum of Tea Ware in Hong Kong, to examine how various semiotic constraints affect the production of English target texts from their Chinese source texts. One such constraint is that of spatial aesthetics, the way in which text is positioned in relation to visually salient pictures or objects in a given ensemble. A second constraint is the generic nature of the text as defined by its position in the museum texthierarchy. Thirdly, the paper argues at greater length that the nature of modification found in the target text is directly proportional to whether the relation between given verbal and visual elements is either paradigmatic or syntagmatic.

\section{MOTS-CLÉS/KEYWORDS}

semiotics, Chinese, museums, syntagm, paradigm 
This paper examines questions of the verbal and the visual in the translation of museum texts. The museum provides a particularly interesting case for discussion, since it represents a complex semiotic environment in which a number of differing systems of signification interact to produce meaning. A given verbal text, for instance, must relate both to other texts within the museum system and to visual signifiers such as objects, pictures and diagrams. In such a system, meaning is thus always "combinatorial and relational" (Hooper-Greenhill 2000: 3), such that no one element within the system can be considered in isolation. The implications for interlingual translation are complex: an individual target text must be considered not simply in terms of its relation to its source text, but also in terms of its relation to other target texts within the museum text-hierarchy, as well as to visual elements. A failure to negotiate such multiple polarities may lead to varying degrees of interpretive breakdown on the part of the end-user (the foreign museum visitor), for whom particular understandings or interpretations available to Source Culture visitors may become restricted or indeed wholly inaccessible. In a bilingual museum environment, a further layer of complexity is added, since both target and source texts must operate side by side within the same museum space and in relation to the same set of visual codes.

The paper begins with a theoretical consideration of these issues, drawing on the discourse of museology. It then focuses more specifically on a single "thematic" museum, the Flagstaff House Museum of Tea Ware in Hong Kong. The museum showcases a variety of tea-related artifacts within a narrative framework that seeks to present a chronological history of tea-drinking and tea-ware in China. The explanatory texts are provided in both Chinese (the source language) and English (the target). The paper seeks to examine how differing verbal-visual interactions within the exhibition space shape interlingual translation practice, and considers examples of verbal texts at differing levels of the museum text system, from introductory wallpanels through to object identification labels. It argues in particular that the relationship between Source and Target texts is directly influenced by the way in which ST verbal elements interact with visual elements, suggesting that where syntagmatic links between such elements become dominant, the parameters of TT modification change, the TT tending to adhere ever more closely to the language of the ST.

\section{Visual-Verbal Interactions in the Museum: Some Theoretical Considerations}

Before embarking on specific analysis of the Museum of Tea Ware, it is worth mapping in more detail the nature of semiosis in the museum environment. In recent years, museology has come to regard the museum as an "expository space" (HooperGreenhill 2000/2004: 557) in which a whole variety of signifiers function as a "text" system. The various semiotic interactions taking place within this space work at both "intra-semiotic" and "inter-semiotic" levels (cf. Toury 1986/1994 for these terms). Within each realm of signification - whether verbal or visual - a number of differing intra-semiotic interactions may be discerned. In the visual, perhaps the most obvious interaction is that between given objects: the formation of object "clusters" (for instance in a particular showcase) is a commonly acknowledged way of reinforcing a particular interpretive message, involving what Barthes refers to as the production 
of a "myth" through the "concatenation" of object-signs (van Leeuwen 2001: 98). Hooper-Greenhill's study of visual culture in the museum, for example, shows how the same object, when removed from one setting and recontextualised in relation to a different set of objects, can unlock radically different possibilities of interpretation (Hooper-Greenhill 2000: 146-148). Such principles of association between individual objects also hold true for relations between different groups of objects: again, the particular configuration of such groupings will shape interpretation. Still within the visual realm, a number of secondary intra-semiotic interactions also function to highlight differing possibilities of meaning. The relationship between objects and photographic or pictorial material provides a particularly complex example: photographs may be used to reveal further aspects of an object, functioning as a kind of iconic mirroring of the actual artifact, by showing it in close-up, or in situ, or from different angles not available when viewing the artifact itself. Alternatively, as we shall explore further below in relation to the Museum of Tea Ware, they may be used merely as impressifs, images that are less explicative than mood-creating, and which therefore stand in a different relationship to the objects against which they are juxtaposed. Finally, beyond such pictorial or photographic material, we must also make mention of other visual signifiers, such as what Stephen Greenblatt (1991: 49) refers to as "boutique lighting," which involves the use of dramatic lighting as a means to create a sense of mystery or wonder around certain artifacts. ${ }^{1}$

In the verbal realm, a similar number of complex relationships exist between differing forms of text. Verbal texts within the museum tend to be arranged in hierarchies, "according to the place, typography and function of statements in the overall framework of the exhibition" (Jacobi and Poli 1995: 75). The different interlocking genres through which textual messages are instantiated have been variously typologised. In one important such typology, Dean (1994: 110-116) has proposed a set of six key distinctions, running from title signs through to sub-titles, introductory texts, group texts, object labels, and finally "distributed materials." The precise demarcation lines of such genres are blurred and subject to debate, and various subdistinctions could be made: the latter grouping, "distributed materials," for example, represents a vast and amorphous mass of differing texts that might include everything from exhibition leaflets to full-scale exhibition catalogues. The obvious problems of categorization seen here, and the considerable fluidity and variability of practice found within differing museums (Skinner 2001: 70), have led some to question the entire validity of such traditional typologies (Jacobi and Poli 1995: 72). Nevertheless, the notion of broad text hierarchies is one found widely in the literature of museology (e.g., Serrell 1996: Ch3; Hallam 2000: 269), for it provides a useful conceptual framework through which to approach verbal texts in the museum environment.

A crucial point to bear in mind when approaching verbal texts within the museum is the notion of intergeneric complementarity, a form of intertextual practice in which the differing text-genres within the hierarchy function in a mutually complementary relationship that may take various forms. These may include simplification (in which, say, a leaflet text functions as a simplified version of the longer wall-panel text), supplementation (in which one text significantly expands on the information provided in another) and differing forms of alternative textualisation. These interactions have hitherto received little scholarly attention and remain to be fully investigated. However, what at least seems clear is that such differing texts func- 
tion, to a greater or lesser extent, as intralingual translations of one another, serving to present similar information about given objects or themes from a variety of different interpretive perspectives. The resultant multi-faceted approach is of crucial importance to learning on the part of the visitor, since the imparting of information from differing angles not only seeks to reinforce more effectively a central message, but also allows for a variety of cognitive levels among a diverse audience, thus ensuring maximum pedadogical potential. As we shall see below, interlingual practice in the museum environment often exploits such complementarity as a means to achieve greater flexibility in regard to what information is selected for inclusion in a given target text.

The various verbal and visual intra-semiotic interactions outlined above in turn function together at an inter-semiotic level to produce meaning. The precise nature of the interaction will depend on the aims of the exhibition in question, and by extension, the ratio of visual to verbal elements. The form of "text" created by this verbalvisual fusion might be described as "multi-modal," if by that term we understand "any text whose meanings are realized through more than one semiotic code" (Kress and van Leeuwen 1996: 183). ${ }^{2}$ As Kress and van Leeuwen have argued, multi-modal texts function in a non-linear way, in which readers make up their own "reading path" to negotiate the various elements on the page. Such non-linear texts, they suggest, "impose a paradigmatics" on the reader (1996: 223), in direct contrast to more traditional forms of linear texts, in which a syntagmatics represents the dominant mode of reading. As such a multi-modal text, the museum text system is likewise subject to forces that suggest a paradigmatic approach on the part of museum visitors. Falk and Dierking, for example, have observed that the visitor experience is often non-linear. The findings of a study carried out by the authors indicated that "visitors in this study did not interact with the exhibit clusters in a linear or sequential manner, even in the very linear Transportation exhibition cluster" (2000: 122). Whilst such a "paradigmatic" mode of visitor experience might in some sense be said to encourage the formation of personal perceptions along the lines of a more constructivist educational approach, it is also true that the paradigmatic tendencies within the exhibition space can easily exert an excessive kind of "centrifugal" force, in which broader messages and themes dissolve in an ill-defined amalgam of disjointed facts and half-understandings.

It is perhaps for this reason that verbal texts are viewed as a crucial braking force on the paradigmatics of the museum, serving to check the potential for interpretive chaos by reasserting a syntagmatics of reading. As Schiele (1995: 38) has noted, "the text controls the decoding of the exhibition, in order to limit the latter's polysemy." Falk and Dierking's study (2000: 122) draws similar conclusions:

[The] presence of consistent, reinforcing conceptual organizers [such as a high density of explicit labelling] on every element facilitated comprehension of the exhibit messages and compensated for the random pattern of visitor utilization.

In the realm of visual-verbal interaction within the museum, then, it is the verbal which is seen as the driving force behind interpretation - an observation reinforced by a number of other empirical studies (e.g., McManus 1991: 39-40) - for the visual represents a particularly "open" system of signification (Hooper-Greenhill 2000: 4), whose meanings must be at least partially fixed by textual interpretation. If such 
dominance - or hegemony, as some might perceive it - of verbal texts in the verbalvisual relationship has come to characterize much of present representational practice in the museum, it is worth noting that this was not always the case. The situation in pre-Enlightenment Europe was one in which verbal and visual modes enjoyed a more equal footing. It was only subsequently that a reconfiguration took place, in which "[the] reification of print-based language [became] the master paradigm for all serious signification” (Stafford 1994: 284, cited in Hallam 2000: 270).

The tension between syntagmatic and paradigmatic styles of reading in the museum and the ways in which such styles affect visitor experience have also been explored by museologists working in a "figurative" (Carbonell 2004: 4-7) interpretive framework. Mieke Bal, for instance, is one prominent art theorist who has suggested that artifacts in the museum environment may be read either "synecdochically" or "metaphorically." In a synecdochic mode, as the term implies, we read objects as synecdoches, as parts of a greater whole, in this case a particular culture or tradition. Such is the case in "ethnographic museums," in which "the artifact is only readable as culture, no matter what aesthetic qualities it may have" (Bal 1996a: 206). In art museums, by contrast, it is the metaphoric mode of reading which predominates: artworks are understood as "standing for a particular aesthetic, and as such, they are considered metaphors" (ibid.), which do not require us to understand them as parts of a cultural whole.

In such a scheme, it would seem clear that the reading of objects as either synecdoches or as metaphors is directly contingent on whether an exhibition favours a syntagmatic or a paradigmatic mode of presentation. For, where syntagmatic links between objects, texts and the various other signifiers within the exhibition space are strong, certain angles of interpretation are made explicit. As Davalos (1998/2004: 528) notes: "Constructed as artifacts and not fine art, objects are displayed along with didactic labels, charts, time lines, tables, or diagrams and with other objects," a situation which leads to the kind of guided comprehension (or "limited polysemy," to recall Schiele's phrase) witnessed in Falk and Dierking's study above. By contrast, where such explicit signification of historical and cultural context is consciously "erased" (Davalos 1998/2004: 527), as in the art museum, the connections both between different artifacts within the exhibition space, and between artifacts and their contexts, are left unspoken, triggering a switch from a syntagmatic to a paradigmatic mode of reading, in which the viewer is forced to make connections for themselves, to try to interpret objects' "subliminal indices" (Hooper-Greenhill 1991: 54-5), in short to read "metaphorically."

If such a distinction is said to underpin the difference between ethnographic and art museums, it should nonetheless be noted that such modes are rarely mutually exclusive, and that differing exhibitions may use differing modes at a given time, as we shall discuss further in relation to the Museum of Tea Ware. Moreover, in a bilingual museum context, both modes may operate simultaneously according to the linguistic resources provided. Bal (1996a: 207; 1996b: 81-2) offers an insightful account of her experience at a Czech ethnographic museum: for Czech readers, the explicit labeling of objects and their significance facilitated a synecdochic reading; for a non-Czech-speaking visitor such as Bal, the absence of any English translation meant that only a metaphorical reading was available, resulting in a quite different response to that intended. Such examples illustrate well the extent to which the era- 
sure of verbal information limits or precludes the possibility of reading visual signifiers (in this case objects) in a synecdochic way. It should be added here that erasure is not the only factor limiting such a reading: ill-conceived or ineffectively constructed verbal information will impose similar constraints, either by obscuring interpretation or by causing such demotivation and frustration that users simply "opt out" of the interpretive process altogether (Screven 1995: 98).

The way in which greater syntagmatic links between verbal and visual elements lead to a more synecdochic reading might be developed further from the perspective of what Scollon and Scollon (2003) refer to as "place semiotics," the study of signs in terms of their spatial positioning within a given location. As Sebeok (1994: 21-2) makes clear: "aspects of a sign necessarily co-occur in an environment-sensitive hierarchy" in which the functioning of the sign may "oscillate," e.g., between an "indexical," "symbolic" or "iconic" mode of signification. When museum objects stand alone, without explanatory text, they have a particular semiotic status: if, as Bal suggests, they speak as "metaphors," then we would expect them to function in semiotic terms as symbols or icons, since metaphor is a trope based on resemblance (the quality that obtains in the case of symbols or icons), not on contiguity (which obtains in the case of indexes). By contrast, to function as synecdoches of a culture, those objects must signify as indexes. It would seem, then, that the presence of explanatory text plays the vital role of "indexicalising" objects, occasioning a switch - an "oscillation" - from symbolic to indexical signification. For, indexicality may obtain "when a sign [in this case the verbal text] makes its meaning by ... its placement together with another sign or object" (Scollon and Scollon 2003: 133). In the museum, verbal texts index visual objects, a reaction which has the potential in turn to indexicalise that object, making it function as an index, in this case a synecdoche. Whether this potential is realized will depend on the strength of the verbal-visual syntagm. When syntagmatic links between verbal text and visual object are at their strongest, that is, when the verbal text shows a particularly high degree of deixis in relation to the object (as in object labels - see later below), such textual indexicality is described as "exophoric" (Scollon and Scollon 2003: 153), a term developed from linguistics, where an "exophor" denotes a special type of anaphoric relation in which the antecedent exists outside and beyond the text. Just as "the name 'Dell ${ }^{\oplus}$ on this computer is read exophorically as "This is a Dell ${ }^{\oplus}$ computer"' (ibid.), so too the label which states - whether explicitly or implicitly - that "this object is a $9^{\text {th }}$ Century pot." By contrast, when syntagmatic links between verbal and visual signifiers are weak, no such exophoric relation obtains. The object or picture in question thus remains non-indexicalised, and hence continues to be read in an essentially metaphoric way.

\section{Visual-Verbal Interactions: The Case of Wall-Panels}

With these theoretical considerations in mind, let us move to a more detailed examination of verbal-visual interactions in The Museum of Tea Ware, and their implications for interlingual practice. As its name suggests, the Museum is a small "thematic" museum which presents a variety of predominantly ceramic artifacts related to the culture of tea-drinking in China, chiefly teapots, cups and bowls. Clearly, such objects might be read in purely aesthetic terms. However, in common with other such thematic exhibitions, they are presented according to a particular 
"narrative framework" (Schiele 1995: 42), in this case a chronologically ordered account of tea-drinking through the various periods of Chinese dynastic history. In addition, information is also provided within this historical narrative as to particular tea-making processes, which whilst historically grounded, are in continued use today. In this way, the museum seeks to link past and present practice, providing both diachronic and synchronic perspectives on the central theme, an approach which clearly privileges a synecdochic reading - a reading of the objects "as culture." The text-hierarchy of the museum is used to reinforce this narrative structure, with "group texts" (Dean 1994: 113-4), at the higher end, being labeled simply by dynastic titles and dates (e.g. "Ming dynasty (1368-1644)"), and more focused text-panels providing additional information on specific methods (e.g., "Steeped Tea"). At the lowest level of the hierarchy, object labels are used to convey both historical and aesthetic information about individual artifacts.

We begin at the higher level of this text-hierarchy by examining the case of a wall panel entitled "Qing dynasty (1644-1911)." The status of this panel deserves comment. Since it introduces a room in the museum dealing with a particular historical period, it must clearly be read as a "group text." Equally, its positioning inside a single showcase in an ensemble that includes not only a picture (a photographic reproduction of a classical painting) but also a set of objects, sets up possible interpretive ambiguities: if the text addresses the whole room, to what extent does it also address the individual showcase in which it is located? In the following, we will examine in more detail the ways in which these ambiguities are played out in the various verbal-visual relationships within the ensemble, and their implications for interlingual practice. We begin by first briefly considering the relationship of the Chinese source text to its English version. The texts read as follows:

\section{Example 1:}

清代 (1644-1911)

清代飲茶仍以泡茶法為主。茗家對茶劽的質素要求更高。一般都以造形淳樸簡 潔, 泡茶能發揮茶的色、香、味的宜興砂彀為茶具的首選。其次為耐暖的錫壼及 精緻的瓷壼。此外，人們還普遍採用蓋杯沏茶。一則可獨卙獨酌; 其次在禮節上可 用以端茶奉客。在制茶的工藝上, 清代造茶者除大量生產綠茶外, 更創制出各類 的紅茶和烏龍茶, 令飲茶者有更多選擇。

\section{Qing dynasty (1644-1911)}

People of the Qing dynasty followed the tradition of the Ming dynasty in preparing tea by the "steeping method." More attention was paid to the decoration of teapots used. Purple clay teapots made at Yixing were still the favourites of tea lovers because these teapots were said to be the best ones in bringing out and retaining the colour, flavour and aroma of tea. Teapots made in pewter and porcelain were also treasured by some tea epicures because the former could keep the tea warm for a longer time while the latter had the feeling of cleanliness. Besides teapots, people of the Qing dynasty also used covered teacups for brewing tea. Covered teacup was an ideal utensil for preparing tea for one person. Tea manufacturers of the Qing dynasty invented the special method to control tea fermentation, whilst resulted in the production of black tea and oolong tea. From the Qing dynasty onwards, people had more choices in the selection of tea. 

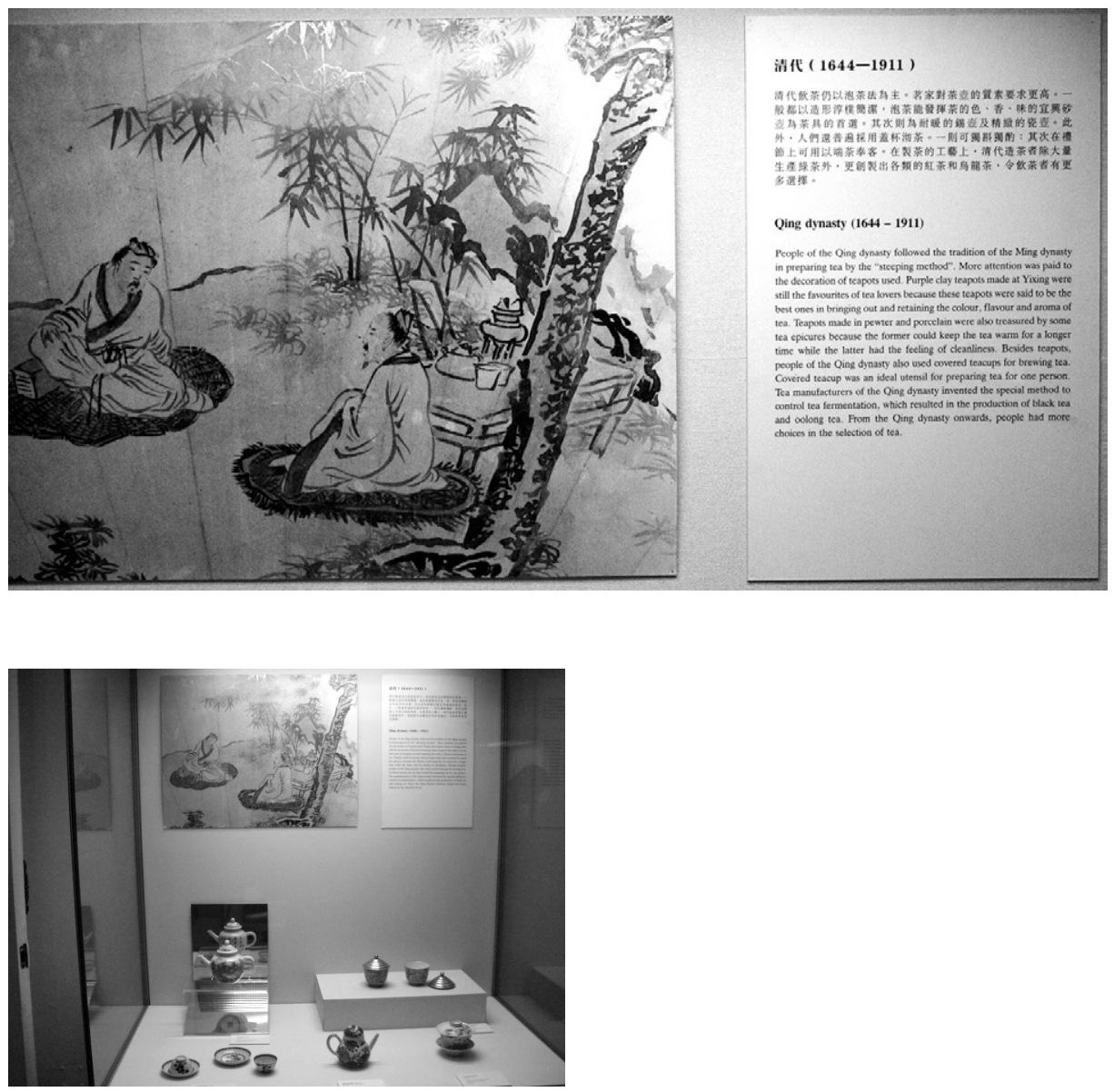

A comparison of the two texts reveals a high level of textual modification in the TT, in which two broad approaches - either reduction or expansion of ST information - are realized through a variety of different strategies. With regard to textual reduction, we find significant portions of ST information omitted throughout the TT version. In the second sentence, for instance, the TT simply tells us that "More attention was paid to the decoration of teapots used," where in ST, there is the additional insight that "in general, they were modeled in simple, clean forms" ("yiban dou yi zaoxing chunpu jianjie”一般都以造形淳樸簡潔). Again, further into the text, TT tells us simply that "Covered teacup [sic] was an ideal utensil for preparing tea for one person," a rendering which compresses information by paraphrasing as a single observation what in ST is phrased as two statements: "Firstly, it could [be used for] personal drinking purposes; secondly, it could be used as a form of etiquette to serve tea to a guest" "“yi ze ke du zhen du zhuo; qici zai lijie shang ke yong yi duancha fengke" 一則可獨勘獨酌; 其次在禮節上可用以端茶奉客). And to cite a third example, in the final description regarding the production of black tea, the ST phrase "besides largescale production of green tea ..." (“chu daliang shengchan lücha wai” 除大量生產綠 茶外) is likewise omitted. 
Alongside such reductions, certain expansions in the TT are also discernable. One particularly noticeable such expansion is the greater foregrounding of historical period markers. Thus in Line 1 of the TT, the phrase "followed the tradition of the Ming dynasty" is not present in ST. Further down, in the phrase "Besides teapots, people of the Qing dynasty...," the dynastic reference is likewise an addition. The same is true of the phrase "From the Qing dynasty onwards" that begins the final sentence. In all, where the ST contains merely two such dynastic markers, TT contains five. Elsewhere, other phrases are added, for instance in the concluding portion of the text, where TT states that the Qing dynasty "invented the special method to control tea fermentation."

Such reduction or expansion of textual information, realised through a variety of strategies, represents an attempt to negotiate a number of differing forces acting upon text production. To begin with, the translation is restricted by spatial considerations, an issue which, whilst perhaps of minor importance when translating between cognate languages such as English and French, takes on a key significance when translating from Chinese to English. Chinese is a considerably more compact language, both grammatically and orthographically: it can convey the same message in half the physical space that it takes to say it in English. In the museum environment, where spatial relations take on greater importance, and where textual space may be at a premium, such a difference becomes a crucial factor that shapes interlingual practice in a number of ways.

If we consider the Source and Target texts together with the visuals (the picture) beside which they are juxtaposed, several spatial relationships are evident. Firstly in this verbal-visual ensemble, it is the picture which has greatest "salience" (Kress and van Leeuwen 1996: 212-214), occupying an area at least twice that of the Source and Target texts combined. Its position at left further enhances this visual dominance, since we tend to "read" such an ensemble much as we would a traditional verbal text, namely from left to right. The text at right is constructed in such a way as to maintain this balance: not only is its width obviously much narrower, but its length likewise also stops well short of the bottom of the picture. In terms of purely visual balance, then, its configuration with the picture is somewhat similar to that of a verticallypositioned caption. Were a longer text column to be created by the use of a longer TT (or, for that matter, a longer ST) the entire visual balance of the composition would be upset.

A similar observation also holds for the spatial relations at an intra-semiotic level, namely between the two verbal texts at right: again, an excessively long TT, running to the bottom of the panel or, even further, into a second column of text, would create a sense of visual imbalance, a sense of excessive dominance within a shared bilingual space. It is of course almost impossible to arrive at an English translation - even a heavily edited version - that is as spatially compact as its Chinese source, and as can be seen in the present example, the TT still occupies a greater space. Nevertheless, a certain sense of counterpoint is maintained by the fact that in this ensemble, the Chinese text occupies a position of greater salience than the English, being placed in the upper position. As Scollon and Scollon (2003: 158) have noted, this positioning is a key means of expressing what is known as "code preference": "When there are two languages in use in bilingual notices, the code preference system positions the upper-most or left-most of two languages as the preferred code." 
The set of values motivating such preference will vary, even within a single society: in Hong Kong, upon which the authors focus, differing preferences are seen, the motivations for which might variously be "geopolitical ideology ... pragmatic convenience ... [or] current fashion" (2003: 124). In the present case, spatial counterpoint, as noted above, is clearly one such motivation. Another may also be the essentially Chinese thematic nature of the Tea museum. For certainly, in another regional museum, the trilingual Museum of Macau, code preference is consciously employed as a means of cultural signification. In exhibition segments relating to Chinese traditions in the region, the Chinese text is placed first; by contrast, segments relating to Western traditions have the Portuguese text placed first. English is in all cases placed third: whilst English-speaking visitors almost certainly outnumber those competent in Portuguese, English culture has been of comparatively little importance to Macanese history, and hence English is treated as a "peripheral code" only.

In addition to these spatial constraints - both inter- and intra-semiotic - on text length, there is the additional factor of genre conventions. As Dean (1994: 114) reminds us, "group texts typically require the greatest effort to read since they contain a major portion of the verbal interpretive message." They must therefore be constructed in a way that is succinct and accessible enough to ensure that visitors do not simply pass them by. For Dean, the optimum length for such texts is 75-150 words, a stipulation to which our "Qing dynasty" wall-panel TT almost exactly complies, being 152 words in length. From a genre point of view then, any attempt to make such a text longer would simply be counter-productive, the sense of verbosity and information overload leading to reader frustration, and hence ultimately to a less informed reading of the museum. Length, of course, is but one element of a text's generic make-up, and clearly, within the length requirement, a generically appropriate structure must be adopted. If such a point seems self-evident, it is clearly not always so in Chinese museum translation practice. As Neather (2005) has observed, the translations of panel-texts at the Confucian Temple in Beijing represent a particularly extreme case, in which a three-paragraph Chinese ST is rendered into English by providing a highly literal translation of the first paragraph whilst simply cutting wholesale the second two paragraphs. The result is a TT which is not only questionable in its length (a mere 70 words), but which is also wholly inappropriate in terms of information density and generic structure.

The combination of these various constraints, then, exerts a considerable pressure on the amount of ST information that can be replicated in the TT. The sometimes drastic reductions that these constraints entail must be balanced against the competing need for expansion of information, of the kind we touched on above. Such expansions may be necessary for various reasons, most obviously linguistic (such as the switch from paratactic to hypotactic structures that frequently occurs when translating from Chinese to English), or cultural, where TT readers lack what Parker (1996) refers to as the appropriate museum "schema" to understand un-glossed ST information. In some cases, a combination of factors may be at work, for instance in the "Qing dynasty" panel, where the foregrounding of dynastic references serves both to reinforce a potentially alien chronology and to add greater textual cohesion than would be required in Chinese. There is thus a sense in which ST and TT exist together in a kind of interlingual version of the information "layering" that is frequently found in 
museum texts, in which different pedagogic levels of the target audience are addressed through differing portions of a given text (Serrell 1996: 68-82).

So far, we have discussed some of the competing forces influencing the production of the Target Text, in particular spatial considerations. Yet how do non-spatial aspects of the verbal-visual relationship influence TT modification? In the "Qing dynasty" example, the text provides a general historical introduction to Qing dynasty tea-drinking, tea-ware traditions and tea-production. Yet the picture provides us with a quite different set of information, depicting two male literati in relaxed conversation amid a bamboo glade, a table with tea utensils to their right. The picture provides no direct illustration of the verbal text passage; likewise, the passage gives no description of the scene depicted in the painting. Indeed, we are told nothing at all about the painting, whether the scene it describes, or the specifics of its composition. In this particular interaction, then, we see a disjunction between word and image, in which syntagmatic links at an inter-semiotic level are weak. Verbal and visual are merely juxtaposed in a kind of inter-semiotic parataxis, in which we are forced to make sense of the image in a paradigmatic fashion, finding our own interpretive links between visual and verbal elements. As we discussed earlier, such a paradigmatic dominance requires that we read links "metaphorically." For this image is not intended to be understood "synecdochically," as an artifact to be slotted into its particular historico-cultural niche, but rather is designed to act as an impressif, a "mood-creator" that conjures up a highly impressionistic vision of tea-drinking in classical China. This observation has important implications for interlingual translation, for as we shall argue further below, when such a syntagmatically weak relationship exists between verbal and visual elements, the parameters of modification in the Target Text remain very loosely defined.

Thus far, we have discussed the interaction of text and picture in this ensemble. Yet what of the other key visual component - the objects - also located in this same case, arranged below the text and picture? Here too, we argue that the relationship between visual and verbal elements is fundamentally paradigmatic, though less categorically so than in the case of the text and picture. Let us first consider the objects displayed. They comprise various porcelain teapots of relatively elaborate design, as well as examples of covered teacups. When we refer again to the panel text, we note that certain of these objects or their features - namely covered teacups, porcelain teapots, and the increased use of decoration - are mentioned, at a general level. As such, we may say that, whereas the relationship between text and picture is wholly "disjunctive," that between text and objects does show a certain increase in cohesion: syntagmatic links are somewhat stronger. Nevertheless, the level of deixis existing between these objects and their textual references ultimately remains weak: rather than being discussed specifically as "these objects," they merely stand as broad exemplars of general categories referred to in the text. Moreover, certain key objectoriented references made in the text, specifically the mention of "purple clay teapots made at Yixing" and "teapots made in pewter" are not visually available within the case, a fact which only further enhances the sense of dislocation between text and objects. Such a situation is at least in part a result of the ambiguities - mentioned earlier - that are set up by placing this group-text within a specific display case: exhibits of pewter teapots and Yixing wares are located in other cases within the "Qing dynasty" room, and therefore must be referred to in the group text, yet they are not displayed within the case in which that text is located. 
The extent of linkage between these objects and the wall text located above them can be further gauged by considering how far they might be said to function as synecdoches. For, we recall that to function as a synecdoche, an object must first be "indexicalised" by an accompanying text. For that indexicalisation to occur, a sufficiently strong syntagmatic relationship is required between text and object. In the case of these objects, such links as discussed above are still insufficient to achieve the required "oscillation" in the status of these objects from symbols to indexes. They remain at best broad and incomplete illustrations of a vaguely-defined thematic unit, "the Qing dynasty," their precise cultural niche and significance still largely closed off to the non-initiated viewer. Whilst their relationship to the text is clearly stronger than the pictorial impressif, a similar sense of visual-verbal parataxis predominates.

In our analysis of the above ensemble, then, we have seen how spatial considerations between the verbal and pictorial material exercise a key constraint on the production of the TT, entailing various modification strategies that must balance the need to cut down TT length with the need to provide additional explanatory material. As we have seen, the resultant TT shows extensive modification. The extent and the nature of this modification, we argue, would seem directly influenced by whether the relationship between verbal and visual elements (including both pictures and objects) is fundamentally syntagmatic or paradigmatic. In the "Qing dynasty" panel and other similar panels within the museum, in which a paradigmatics of reading prevails, a considerable degree of fluidity is found in respect of modification: cutting or expansion strategies are employed throughout the text as necessary. What is interesting to note, however, is that within this, ST elements having a possibly stronger syntagmatic linkage (even though still too weak to achieve indexicalisation of the objects in question), tend to be retained in the TT: where processes or other issues referred to in the ST may be cut, object-related references are generally preserved, even if they are expressed in a more compacted form, such as the reference to the covered teacup in the "Qing dynasty" panel.

A more graphic illustration of this tendency is found in another, similar group text dealing with the "Ming dynasty (1368-1644)." The layout of the ensemble in which this text panel is located is essentially the same as in the "Qing dynasty" example: again, a picture at left is juxtaposed with a bilingual text at right, and an array of porcelain teapots is located below. Likewise, a certain ambiguity is set up by the fact that the text addresses the whole "Ming dynasty" room in the museum whilst at the same time being located within a specific display case.

If the Source and Target texts of this panel are compared, an interesting shift can accordingly be seen in the way that the TT is modified. The texts read as follows:

\section{Example 2:}

明代 (1368-1644)

到明代, 葉茶的生產基本上已完全取代了團茶的地位。飲時不再碾茶成末, 而是 全葉冲泡。泡茶法雖不若唐、宋的煎、煮、噍點那樣繁複, 但亦有其細緻的工 序。(詳見本展覽廳圖解)。泡茶法不單注重茶量、水溫、火候、茶喆的型製也十 分講究。明代初期多以丈劽泡茶。然而茶葉浸包過久則鮮味不存, 且變得苦澀, 所以茶瑴的形狀由大轉細。人們除喜愛青花及白釉的茶具外, 更以宜興所產的紫 砂锓為泡茶極点。 


\section{Ming dynasty (1368-1644)}

In the Ming dynasty, people used a different method in making their cups of tea. They preferred to prepare tea by steeping refined tea leaves in a teapot. This was called the "steeping method." In order to prepare a good cup of tea by using the "steeping method," the amount of tea leaves used and the water temperature have to be carefully controlled. At the beginning of the Ming dynasty, people used large teapots to brew tea so that they could drink many cups from one pot of tea. Later, they discovered that when the tea leaves were being steeped too long in hot water, the tea would become bitter in taste and the last few cups would not be as fresh as the first few ones. That was why the size of teapots became smaller and smaller. Apart from underglazed teapots and white glaze teapots, those teapots made in purple clay at Yixing of Jiangsu province were most treasured by the tea epicures.

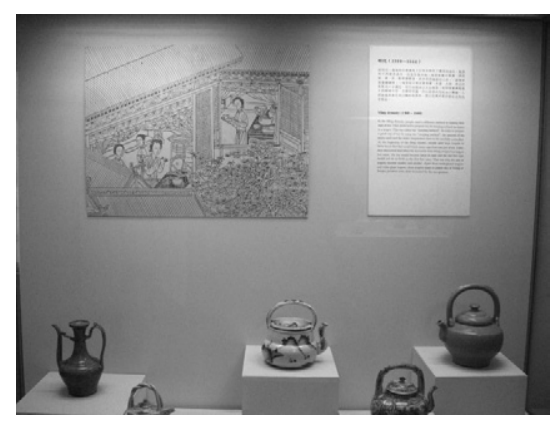

As in the "Qing dynasty" panel, here too a considerable amount of modification both reduction and expansion - is seen. However, the distribution of such approaches in the TT is noticeably different. Evidence of reduction-strategies is found almost exclusively in the first half of the text. To cite just two striking examples, in the opening, ST tells us that " the production of leaf-tea had basically completely replaced that of 'balled-tea'"' ( yecha de chansheng jiben yi wanquan qudaile tuancha de diwei 葉 茶的生產基本上己完全取代了團茶的地位); again, we learn that the brewing of tea in the Ming period "was not as complicated as the roasting, boiling, infusing and 'dipping' methods of the Tang and Song dynasties" " "bu ruo Tang Song de jian, zhu, peng, dian nayang fuza 不若唐、宋的煎、煮、烹、點那樣繁複). Such omissions are clearly made on the basis that, given spatial constraints, the kind of cultural information found here, including a number of specialist terms for which no direct equivalents are available, would be simply too complex to convey succinctly (cf. Gill 1994: 781). It should be noted, however, that the need for such omissions has been at least partially compensated for by exploiting what we earlier termed "intergeneric complementarity," the notion that differing text genres in the museum present similar information in differing ways, such that they function to a greater or lesser extent as intralingual translations of each other. Thus, the references to the Tang and Song dynasties, conspicuously absent here, are instead incorporated in a different text entitled “Steeped Tea” (pao cha fa 泡茶法), which introduces a series of photographs demonstrating this method of brewing tea.

The nature of modification in the "Ming dynasty" TT shifts dramatically in the second half of the text. From the sentence starting "At the beginning of the Ming 
dynasty...," any such omissions have been rigorously avoided; instead, all salient ST material is accurately reproduced, any textual modifications instead taking the form of expansions. The results of such a shift in approach are strikingly apparent in the spatial configuration of the two passages. Where the corresponding ST phrase, "Ming dai chu qi...”明代初期 occurs in Line 5 of a text just over seven lines in length, the English phrase "At the beginning of the Ming dynasty..." starts Line 6 of a thirteenline passage. Such a configuration cannot be explained by the idea that information has been restructured and reapportioned to different parts of TT: it has not. TT information flow generally adheres closely to ST. Rather, it is the case that information in the first half has been heavily cut, allowing a full rendering of the detail in the second half of the text.

Such a configuration would seem directly related to the content of the text. Where the opening deals with such developments as the "steeping method" (developments also described in more detail elsewhere in the exhibition) the text has been cut; where later it describes the development of tea-ware, by contrast, it has been kept in full, and even expanded. This choice of content in turn relates directly to the way in which these verbal elements are juxtaposed with visual signifiers. As we noted in the "Qing dynasty" panel, whilst the whole ensemble is informed by a paradigmatics of reading, in which picture, objects and text are only loosely connected, elements within ST that relate more closely to the visual material (in this case the objects) are retained in translation. Whilst relations of exophoric indexicality between objects and text remain too weak to indexicalise the objects (and hence make them fully readable as synecdoches), there is nevertheless an attempt in translation to preserve the stronger syntagmatic potential of the object references. Thus, where such references occur, TT follows ST more closely, opting for a full translation of ST information. In order to negotiate spatial constraints, this is balanced by a significant cutting of information where the syntagmatic links are weaker, i.e., where the text relates less directly to the visual signifiers displayed.

\section{Strengthening the Syntagm: \\ Pictures and the Description of a Process}

With these points in mind, we shall now turn to examine verbal-visual interactions in which a fundamentally more syntagmatic relationship applies, and in which the restraints imposed by this relationship upon TT modification are more clearly evident. As we shall see, these interactions tend to take place at levels lower in the museum text-hierarchy than those discussed so far. We shall begin with a consideration of what might be termed "process-oriented" ensembles, before moving in the final section of this paper to examine object labels.

The Museum of Tea Ware contains several examples of verbal-visual ensembles in which only text and pictures are present, and which attempt to illustrate particular tea-making processes, such as "Steeped Tea," "Cream Tea" and "Gongfu Tea." These "process-oriented" ensembles may be located in the middle levels of the museum text-hierarchy. They are clearly more specific than the examples of group texts discussed above, yet they belong to a more generalized frame of reference than individual object labels. The relationship between text and pictures in these ensembles is wholly different to that found in our earlier "Qing dynasty" example. Rather 
than functioning as impressifs that merely add metaphorical texture to the texts they accompany, these pictures are arranged as sets, each picture giving a photograph of objects in use at a particular stage of the process in question. Thus "Gongfu Tea," upon which we will focus here, comprises a set of ten different photos, each with an accompanying text caption that is generally short in length and placed directly below the photo. The following is one such example:

\section{Example 3}

\section{(9) 注茶}

Brewing the Tea

把瓷杯排列好, 將茶巡迴注入杯中, 使每杯茶的濃度平均。每一巡要傾盡劽內的 茶湯, 免使茶葉浸泡過久, 變得苦澀。

When pouring the tea into the teacups, the hand holding the teapot has to move in a circular motion in order to ensure each cup has the same quality of tea. No tea is allowed to be left inside the teapot as the second brew may become bitter in taste when the tea leaves are over steeped in water.

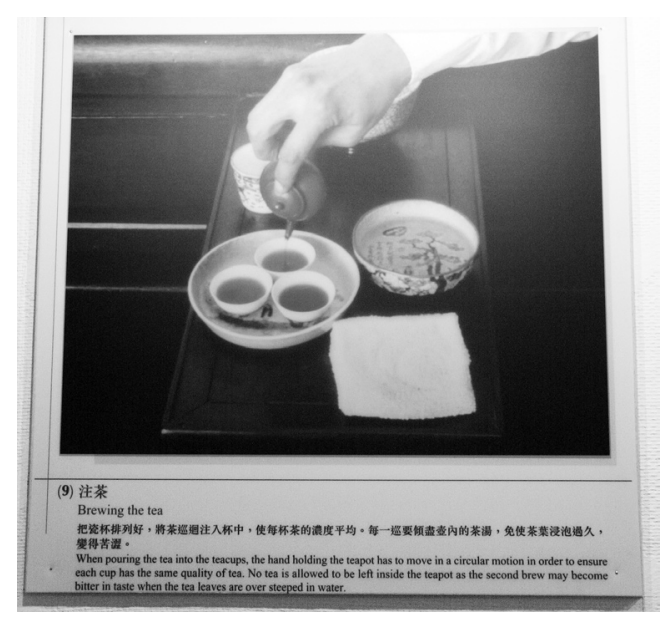

The role of the text here in interpreting its accompanying photo is clearly vital. For, whilst the pictures together are recognizable as parts of a process, the nature of that process remains unclear to the uninitiated viewer, the more so since photographic stills, even arranged in a sequence, are not wholly conducive to illustrating action. In the photo accompanying the above text, for example, it is almost impossible to capture the sense of the circular motion of the pourer's hand as the teapot is moved from cup to cup without stopping the flow of tea. Without the text, then, the viewer would be forced to read the visuals simply in terms of their "subliminal indices," to recall Hooper-Greenhill's term, reading them metaphorically. Only when text is used to indexicalise the pictorial material does the full meaning of the process described by the pictures become apparent. As we have seen, such indexicalisation takes place when syntagmatic links between verbal and visual elements are strong, a situation which obtains in the present case. 
It should be noted that the creation of such a strong verbal-visual syntagm here is important not only for the understanding of this ensemble, but also of other elements displayed elsewhere within the same area of the museum. For in this particular room, "Gongfu Tea" is also addressed in an ensemble whose layout mirrors that of the "Qing dynasty" ensemble discussed earlier. Here too, a picture, text and set of objects are arranged within a single display case in a fundamentally paradigmatic relationship: the majority of objects displayed (which are items used in the process of brewing gongfu tea) are not referred to in the text, which focuses instead on the generalities of gongfu tea, whilst the pictorial impressiflikewise has little obvious relation to either text or objects. Thus, in order to allow a more complete understanding of gongfu tea (which, we are told, refers to both a type of tea and a tea-making process), the need for a complementary and more syntagmatically coherent treatment of the same process becomes crucial, hence the importance of the ten-picture series.

If we turn to examine the English TT in our example, we find a certain amount of textual modification. For instance, the Chinese ST phrases the process in a more instructional tone, whereas in the English, this has been adjusted to achieve a more "expositional" text-type focus, the switch being achieved principally by a shift away from the imperative forms of the ST. In regard to cutting of ST material, however, every effort has been clearly been made to avoid the kind of excisions seen above in our discussion of the group texts. The only such instance is found in the opening, where the phrase “ba cibei pailie hao" 把瓷杯排列好 (“Set out the porcelain cups") has been dispensed with in the TT. This cut, no doubt made for reasons of spatial constraints similar to those discussed earlier, nevertheless does little to weaken the strength of the visual-verbal syntagm, since this information is already visually available to the viewer: the neatly arranged cups in the photo (especially when contrasted with those in the preceding photo in the series, which are in the process of being rinsed) speak for themselves. Any losses in the verbal material are thus compensated for by visual signification.

Similar observations may be made regarding other texts in this series. Only occasionally is more substantial cutting seen, as in the final text of the ten:

\section{Example 4}

(10) 待用

Serving the tea

品嚐功夫茶要淺嚐細啜, 並欣賞茶的色、香、味。

The tea is ready to be served. 


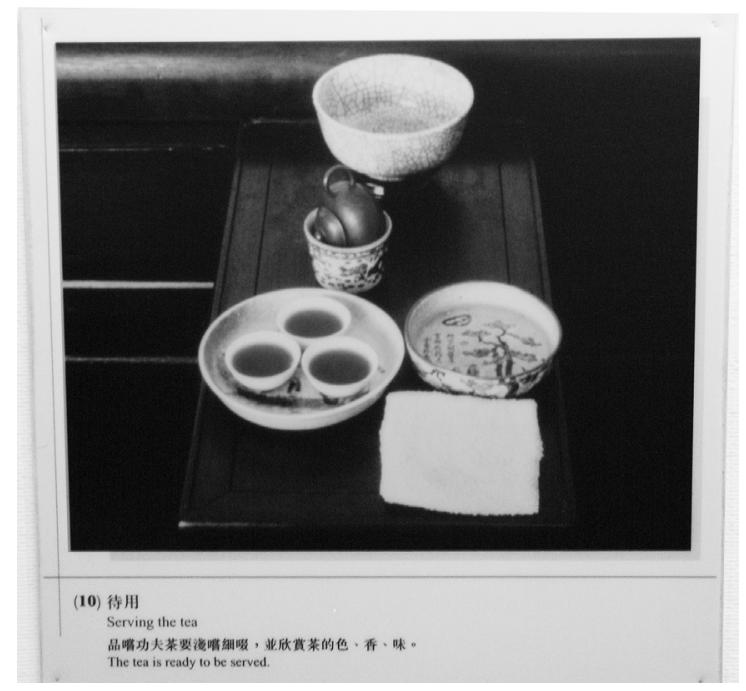

Here, the Chinese information on the tasting of the tea ("When tasting gongfu tea, one should take small and delicate sips, and appreciate the tea's colour, aroma and flavour.") has been reduced to a mere summarizing phrase that simply serves to wrap the process up. The precise motivations for this undertranslation remain uncertain. What is clear, however, is that the omitted information does nothing to affect one's understanding of the process of making this tea, which is the focus of this wall-panel series. Moreover, the omitted material, though not visually available in the accompanying picture, is textually available elsewhere in the exhibition space: the final sentence of the wall panel in the "Gongfu Tea" display case nearby uses very similar phrasing in ST, which is reproduced in the TT: "It is said that such a drinking style is the best way in bringing out the colour, flavour and aroma ...." Here too, then, we recall our earlier assertion regarding the importance of "intergeneric complementarity" between texts as a factor in negotiating the constraints of translation in the museum environment: what is omitted in one text may be compensated for in another text elsewhere. In the following, final section, we shall examine in more detail how such factors are exploited at the lowest level of the museum text- hierarchy.

\section{Labels: Verbal-Visual Interactions Lower in the Text-Hierarchy}

So far we have examined the semiotics of translation practice at the higher and middle levels of the museum text-hierarchy. As we move further down that hierarchy, we tend to find an ever-stronger syntagmatic link formed between visual and verbal material, as texts become still more specific in the way they relate to objects and images. Here, we focus on a particularly acute case, object labels. Dean (1994: 114-5) has identified two main subgenres of object label: captions and "identity (ID) tags." The labels in the Museum of Tea Ware are essentially of the latter kind, providing no more than "a set of descriptive data about an object," which gives "only basic facts such as the name or title of the object, its maker or origin, the material the object is made of, pertinent dates, collection or catalog numbers, and other relevant data" (ibid). Clearly, the syntagmatic links that obtain between the object and its text are 
particularly pronounced: text and object exist in a kind of symbiotic relationship in which the one cannot be understood without the other. For the object to be read in a fully synecdochic way, the label is essential; equally, the label cannot be read independently of the object: its whole structure is underpinned by a strong sense of deixis - it is describing "this particular object" and no other, a situation we referred to in our Introduction as "exophoric indexicality."

If such ID tags might seem too brief a text to warrant consideration, it is worth noting that numerous museologists have bemoaned the lack of attention paid in many museums to the quality of such labels (see for instance McManus 1991: 39; Dean 1994; Screven 1995; Serrell 1996). For, the brevity of their construction, and the particular generic constraints as to what can and cannot be included, in many ways pose particular challenges, both for curators and for translators. The ID tags in the Museum of Tea Ware suggest subtly different approaches to translation which try to preserve the syntagmatic links established by the Chinese Source Text whilst negotiating the severe textual limitations of the genre. In Example 5 below, we see the label that accompanies an unglazed clay teapot (see Fig. 3):

\section{Example 5}
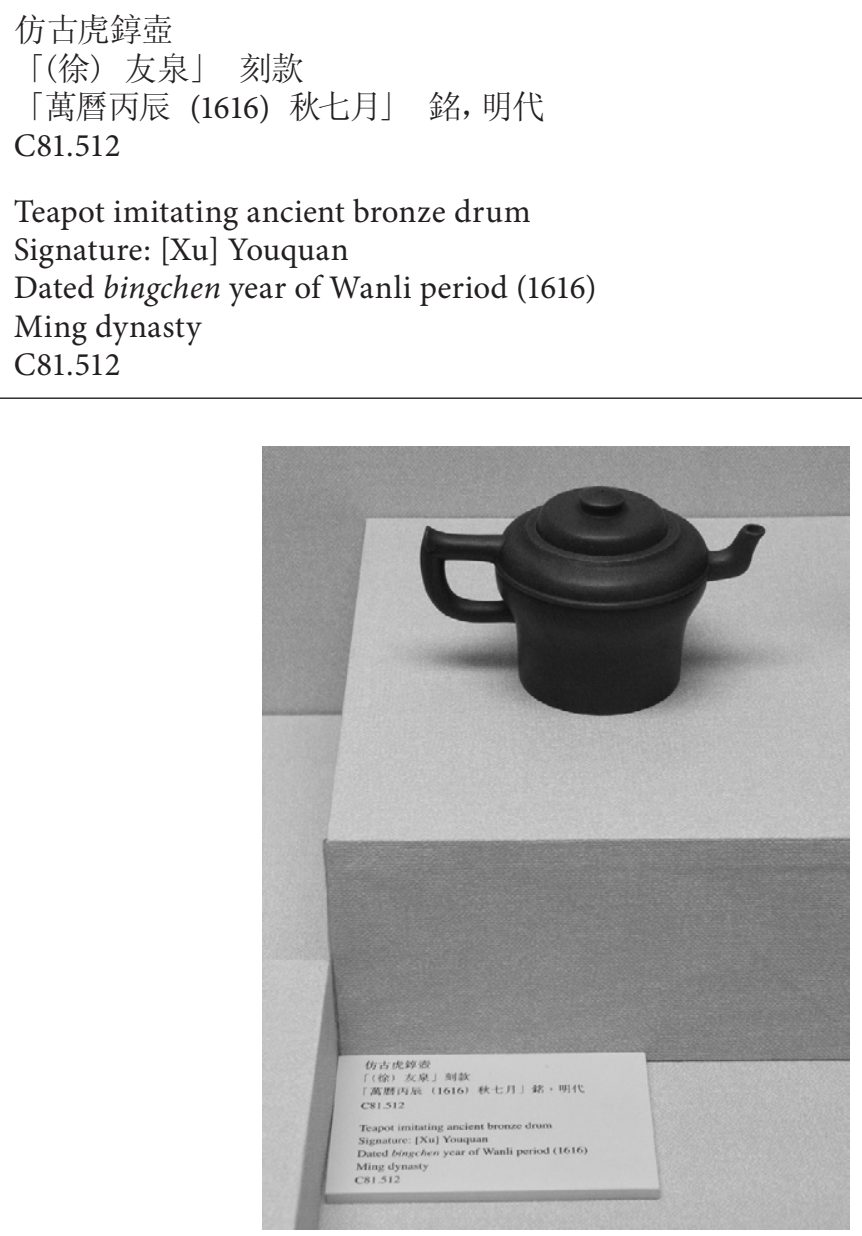
The TT here, and in other examples from the same series of pots, reveals a desire to replicate almost every detail of the Chinese ST. The Target Culture reader is provided with a surprisingly rich level of detail. The pot is first identified as "imitating a bronze drum," a fact essential to our understanding of the object, whose purely visual aspect does not suggest such a reading to the uninitiated viewer. Details are also given of the potter's signature (right down to the surname "Xu," not present on the pot but supplied in brackets by the curator), and of the date of production: the full Chinese dating system is replicated, involving both the "reign title" (Wanli) and the sexagenary cyclical term ${ }^{3}$ for that year (bingchen). The only item that has been omitted is “qiu qiyue” 秋七月 (Autumn, $7^{\text {th }}$ Month), a detail perhaps felt superfluous to an already highly detailed explanation.

In a different series of pots - glazed, with painted designs - a rather different approach is revealed. Consider the following example:

\section{Example 6}

青花花鳥紋茶壳

明代, 約1640年

C88.11

Teapot in underglaze blue

Ming dynasty, c. 1640

C88.11

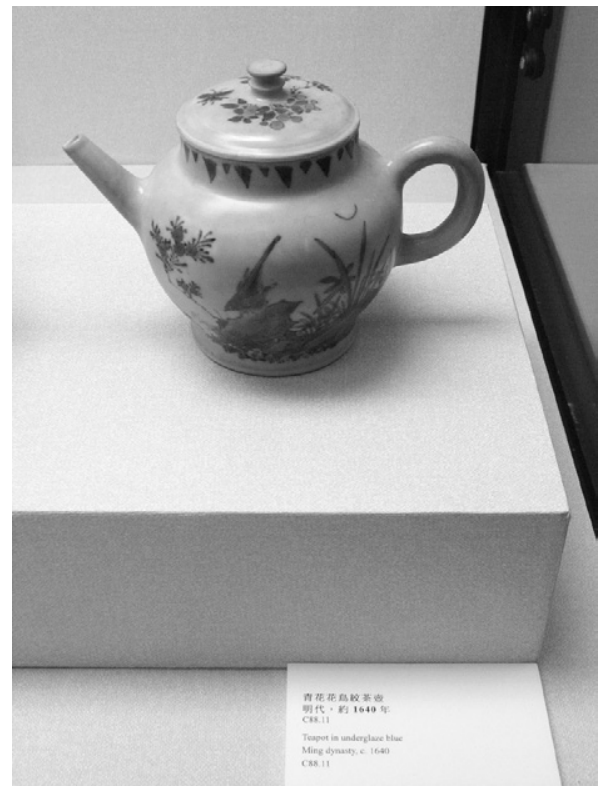

Here, detail is again carefully replicated. However, there is a noticeable omission: “huaniao wen" 花鳥紋, meaning “flower and bird designs," is left untranslated. Further examination of other labels reveals a clear pattern: where iconographical or artistic information is not clearly signified visually (that is, where the design of the 
object is not evident to the viewer), as in the drum-shaped teapot above, it is translated from ST. However, where such information is visually available without the need for verbal elaboration (as here), it is left untranslated (though it is always present in ST). Such a use of omission may reflect a desire to comply with TT norms, as we saw earlier with texts higher in the museum hierarchy, in this case, the need for extreme concision, owing to the severe limits on space, and the need to maintain the salience of the object in relation to the text. It may also be an attempt to avoid information overload, where it is possible to do so. The crucial point, however, is that this verbal information regarding artistic details is only omitted when it is already communicated unequivocally by the visual signifiers. In this way, the syntagmatic links between verbal and visual elements of the broader "text" are not disturbed: every element needed for a synecdochic reading is still available.

A final example of such labeling deserves comment. Again, the following is an ID-tag for a colour-glazed tea-caddy:

\section{Example 7}

青花珐瑯彩花卉紋茶罐

清代, 一七一 0 至三 0 年

$\mathrm{C} 81.158 \mathrm{~b}$

Blue-and-white tea caddy with enamel decoration added in Holland

Qing dynasty, 1710-30

$\mathrm{C} 81.158 \mathrm{~b}$

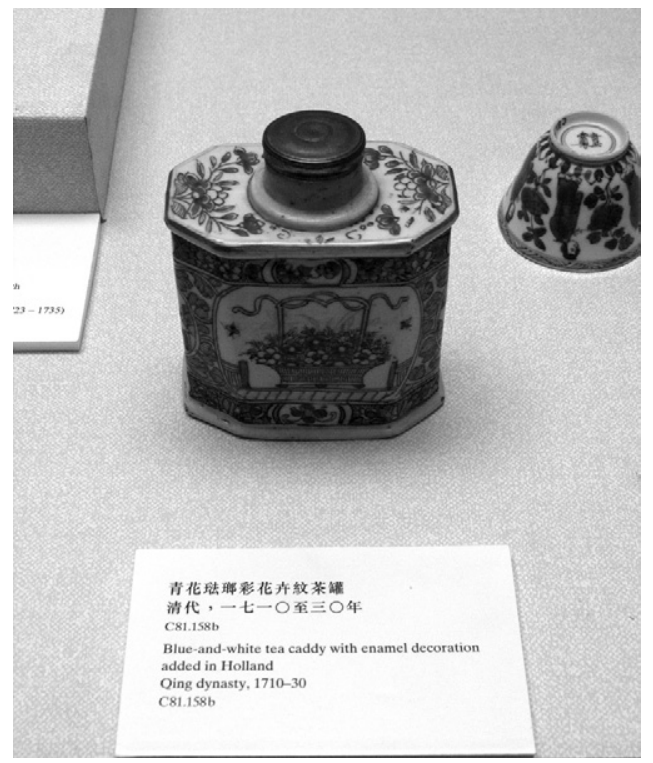

Once again, we see a similar omission of the design details: “huahui wen” 花卉紋 denotes a "floral design"; as with the previous example, this is visually self-evident, needing no verbal elaboration. What is interesting here, however, is the addition of 
a phrase not present in ST: "added in Holland." This phrase (which also occurs in another piece of the same type) represents not merely an elaboration of culturally inaccessible ST details, but may be read as a subtly calibrated addition of information according to the perceived needs of the particular Target Audience. In the Chinese, no such reference exists: either such a detail would already be known, or it is regarded as irrelevant to Chinese viewers, for whom this is still a Chinese-produced piece of "Chinese porcelain." The addition is thus intended to make a link with a cultural world (European porcelain manufacture) with which the educated Western viewer is likely to be able to connect more readily.

In these different labels, then, we likewise see various modifications. In line with our earlier analysis, we observe that here, where syntagmatic links are at their strongest, little if any reduction of ST information occurs. Indeed in many labels, there is a strong tendency towards much greater literalism than seen in texts higher up in the museum hierarchy. Where modification occurs, it takes the form of expansions which suggest that in certain cases, texts are being specifically geared to different audiences within the same bilingual space.

\section{Conclusion}

In the above analysis, we have sought to explore the ways in which interlingual translation is shaped by the semiotics of the museum environment. We have argued that the effective translation of a given verbal text requires an acute understanding of its place in the broader museum text system, a system encompassing a number of differing types of signification, in particular verbal and visual. We have observed that the "multi-modal" nature of this text system entails a paradigmatics of reading whose polysemic interpretive possibilities must be brought under control by the enhancing of syntagmatic links that make the interpretive connections between various signifiers more explicit. In a "thematic" museum, such as the Museum of Tea Ware, such explicit connections are necessary if the objects displayed are to be read as synecdoches, i.e., effectively decoded in terms of their cultural significance.

The constraints imposed upon interlingual translation by such an environment include issues of spatial and visual aesthetics, code preference, genre conventions, and the extent to which the verbal-visual interaction privileges a syntagmatic or paradigmatic mode of reading. Where paradigmatic links between elements in a given verbalvisual ensemble are strong, modifications (whether reduction or expansion of ST material) are freely made throughout the TT. As syntagmatic links become stronger, expansion strategies may still be employed, but correspondingly less reduction is seen, a case most keenly observed at the lowest end of the museum text-hierarchy.

Such observations are of course restricted to interlingual practice in the context of a particular Chinese thematic museum. The extent to which they hold true on a broader scale would require an assessment of other museologico-linguistic situations, for instance translation involving other language pairs, practice in trilingual and quadrilingual museums, and differing types of museum presentation, in particular art museums (as opposed to ethnographic), as well as those which show a greater ideological bias or aim at a larger target audience than the Museum of Tea Ware. What is clear, however, is that in much museological practice, a far greater awareness of the ways in which differing verbal and visual imperatives shape translation is needed. 


\section{NOTES}

1. In semiotic terms, such lighting might be more specifically described as a "connotator," a term which denotes a particular "aspect of the way in which [things] are represented" (van Leeuwen 2001: 97). As van Leeuwen (98) notes, lighting is one of the techniques discussed by Barthes in regard to connotation in photography.

2. A similar point regarding the multi-modal nature of museum discourse is made by Ravelli (2006: 121). At the time of writing this paper, Ravelli's work had not yet been published. A fuller consideration of her findings must therefore await a subsequent paper.

3. "Balled-tea" denotes a type of tea production prevalent in the Song dynasty (960-1279 CE), in which tea was produced in spherical moulds.

4. Chinese years were traditionally counted in cycles of sixty: each year in the cycle was designated by a particular term, formed from a combination of one of the ten "heavenly stems" and one of the twelve "earthly branches." This designation was then combined with the "reign title" of the particular emperor on the throne. In earlier dynasties, a single emperor might change the reign title every few years, to indicate a new era within his rule. From the Ming dynasty onwards, however, each emperor used a single reign title only.

\section{REFERENCES}

Bal, M. (1996a): “The discourse of the museum," in Greenberg, R., Ferguson, B. W. and S. NaIrne (eds.), Thinking about exhibitions, London and New York, Routledge, pp. 201218.

BaL, M. (1996b): Double Exposures: The subject of cultural analysis, London and New York, Routledge.

Carbonell, B. M. (2004): "Museum/studies and the 'eccentric space' of an anthology," in Carbonell, B. M. (ed.), Museum Studies: An anthology of contexts, Oxford, Blackwell, pp. 1-13.

Dean, D. (1994): Museum Exhibition: Theory and practice, London and New York, Routledge.

Davalos, K. M. (1998/2004): "Exhibiting Mestizaje: the poetics and experience of the Mexican Fine Arts Center Museum," first published in Ríos-Bustamante, A. and C. Marin (eds.), Latinos in museums: a heritage reclaimed, reprinted in CARBonell, B. M. (ed.), Museum Studies: An anthology of contexts, Oxford, Blackwell, pp. 521-540.

FALK, J. H. and L. D. Dierking (2000): Learning from Museums: Visitor experiences and the making of meaning, Walnut Creek, Alta Mira Press.

GiLl, M. (1994): “Terms and their translation for museum labels," Meta 39-4, pp. 774-785.

Greenblatt, S. (1991): "Resonance and wonder," in KARP, I. and S. D. LAVine (eds.), Exhibiting cultures: the poetics and politics of museum display, Washington, Smithsonian Institution Press, pp. $42-56$.

Hallam, E. (2000): “Texts, Objects and Otherness: Problems of historical process in writing and displaying cultures," in Hallam, E. and B.V. Street (eds.), Cultural Encounters: Representing "otherness," London and New York, Routledge, pp. 260-283.

Hooper-Greenhill, E. (1991): "A new communication model for museums," in Kavanagh, G. (ed.), Museum Languages: Objects and texts, Leicester, Leicester University Press, pp. 4761.

Hooper-Greenhill, E. (2000): Museums and the interpretation of visual culture, London and New York, Routledge.

Hooper-Greenhill, E. (2000/2004): "Changing values in the art museum: rethinking communication and learning," in CARbonell, B. M. (ed.), Museum Studies: An anthology of contexts, Oxford, Blackwell, pp. 556-575.

JACOBI, D. and M. S. Poli (1995): "Scriptovisual documents in exhibitions: some theoretical guidelines," in Blais, A. (ed.), Text in the Exhibition Medium, Montreal, Société des Musées Quebecois and Musée de la Civilisation, pp. 49-73.

Kress, G. and T. van Leeuwen (1996): Reading Images: The grammar of visual design, London and New York, Routledge. 
McManus, P. M. (1991): "Making sense of exhibits," in Kavanagh, G. (ed.), Museum Languages: Objects and texts, Leicester, Leicester University Press, pp. 33-46.

Neather, R. (2005): "Translation quality in the museum: towards a greater awareness of enduser needs," Translation Quarterly 38, pp. 1-24.

PArker, M. (1996): "Museums: frames and prototypes put in their place," Europa 1, <http:// www.intellectbooks.com/europa/numberl/parker.htm>.

Ravelli, L. J. (2006): Museum texts: communication frameworks, London and New York, Routledge.

Sebeor, T. (1994): Signs: An introduction to semiotics, Toronto, University of Toronto Press.

Schiele, B. (1995): "Text in the exhibition medium," in Blais, A. (ed.), Text in the Exhibition Medium, Montreal, Société des Musées Quebecois and Musée de la Civilisation, p. 33-47.

SCOllon, R. and S. Wong Scollon (2003): Discourses in Place: Language in the material world, London and New York, Routledge.

Screven, C. G. (1995): "Motivating visitors to read labels," in Blais, A. (ed.), Text in the Exhibition Medium, Montréal, Société des Musées Quebecois and Musée de la Civilisation, pp. 97-132.

Serrell, B. (1996): Exhibit Labels: An interpretive approach, Walnut Creek, AltaMira Press.

SKINNER, H. (2001): Making Ourselves Understood: An analysis of current museum text writing practice and its efficacy, Unpublished M.A. thesis, Department of Museum Studies, University of Leicester, United Kingdom.

Stafford, B. (1994): Artful Science: Enlightenment, entertainment, and the eclipse of visual education, Cambridge, MIT Press.

Toury, G. (1986/1994): “Translation: a cultural-semiotic perspective,” in SEвEOK, T. A. (ed.), Encyclopaedic Dictionary of Semiotics, vol. 1, Berlin and New York, Mouton de Gruyter, pp. 1111-1124.

van Leeuwen, T. (2001): "Semiotics and iconography," in van Leeuwen, T. and C. Jewitt (eds.), Handbook of Visual Analysis, London, Sage, pp. 92-118. 